\title{
BMJ Open Lung cancer survival and mortality in Taiwan following the initial launch of targeted therapies: an interrupted time series study
}

\author{
Jason C Hsu (D) , ${ }^{1}$ Chen-Fang Wei, ${ }^{2}$ Szu-Chun Yang, ${ }^{3}$ Peng-Chan Lin, ${ }^{3}$ \\ Yang-Cheng Lee, ${ }^{4}$ Christine $\mathrm{Y} \mathrm{Lu}{ }^{5}$
}

To cite: Hsu JC, Wei C$\mathrm{F}$, Yang S-C, et al. Lung cancer survival and mortality in Taiwan following the initial launch of targeted therapies: an interrupted time series study. BMJ Open 2020;10:e033427. doi:10.1136/ bmjopen-2019-033427

- Prepublication history for this paper is available online. To view these files, please visit the journal online (http://dx.doi. org/10.1136/bmjopen-2019033427).

Received 04 August 2019 Revised 09 March 2020 Accepted 09 April 2020
Check for updates

(C) Author(s) (or their employer(s)) 2020. Re-use permitted under CC BY-NC. No commercial re-use. See rights and permissions. Published by BMJ.

For numbered affiliations see end of article.

Correspondence to

Dr Jason C Hsu;

jasonhsu@tmu.edu.tw

\section{ABSTRACT}

Objectives Two oral targeted therapies, gefitinib and erlotinib, were first approved and then launched into the market for treatment of late-stage non-small cell lung cancer (NSCLC) in Taiwan in 2003 and 2006, respectively. The aim of this study were to determine the trends in lung cancer burden and examine changes in lung cancerrelated survival rates and mortality following the launch of these new drugs.

Setting Yearly lung cancer-related data (1994-2013), including incidence, number of newly diagnosed patients, survival rate and mortality, were retrieved from the Taiwan Cancer Registry Database.

Design and outcome measures Using a time series design with autoregressive integrated moving average model, we investigated and projected trends in the incidence and early diagnosis of lung cancer in Taiwan. We also estimated the changes in survival rates and mortality following the launch of targeted therapies using interrupted time series and segmented regression models. Results The age-standardised incidence of lung cancer increased from 22.53 per 100000 people in 1994 to 34.09 in 2013 , and it was projected to reach 38.98 by 2020 . The rate of early-stage NSCLC at diagnosis increased from $12.63 \%$ in 2004 to $23.99 \%$ in 2013 , and it was projected to reach $32.95 \%$ by 2020 . The 2-year lung cancer survival increased by $19.81 \%$ (95\% Cl $14.90 \%$ to $24.71 \%) 3$ years following the launch of gefitinib. Lung cancer mortality declined by $5.97 \%(95 \% \mathrm{Cl}-8.20 \%$ to $-3.73 \%) 3$ years following the launch of gefitinib.

Conclusions Lung cancer survival rate increased and mortality decreased significantly following the launch of gefitinib and erlotinib in Taiwan.

\section{INTRODUCTION}

Lung cancer is the leading cause of cancer deaths worldwide. ${ }^{1}$ Globally, around 1.82 million new patients were diagnosed with lung cancer $(12.9 \%$ of all cancer diagnoses), and around 1.59 million patients died (19.4\% of all cancer mortalities) in $2012 .{ }^{2}$ The incidence was 23.1 per 100000 people, and mortality was 19.7 per 100000 people in $2012,{ }^{2}$ which has increased over time. ${ }^{1-3}$ In
Strengths and limitations of this study

- This study examined the long-term trends in yearly incidence, the rate of early-stage lung cancer at diagnosis, survival rate and mortality of lung cancer.

- Long-term data from the Taiwan Cancer Registry Database were used in this study.

- A time series design was used to project the incidence and the rate of early-stage lung cancer at diagnosis.

- An interrupted time series design was applied to estimate the changes in survival rates and mortality following the launch of targeted therapies.

- This study did not use patient-level data to separate patients by lung cancer subtypes and disease severity.

the USA, approximately 214000 new cases of lung cancer $(13.3 \%$ of all cancer diagnoses) and 168000 deaths due to lung cancer (27.2\% of all cancer mortalities) were estimated in 2012. ${ }^{3}$

In Taiwan, lung cancer is also one of the most commonly diagnosed cancers as well as the leading cause of cancer deaths. Approximately 12462 new cases of lung cancer $(12.1 \%$ of all cancer diagnoses) and 9167 deaths (19.9\% of cancer deaths) were projected to occur in Taiwan in $2014 .{ }^{4}$ About $85 \%$ of all lung cancers are identified as non-small cell, and approximately $75 \%$ of these are metastatic or advanced at diagnosis, for which no curative treatment is available. ${ }^{5-8}$ Given most patients are diagnosed with advanced stage diseases, it is considered a terminal illness with a 5 -year survival rate of less than $15 \% .^{9-11}$

Oral targeted therapies for non-small cell lung cancer (NSCLC) were launched into the market for patients with epidermal growth factor receptor (EGFR) mutation in Taiwan in 2003 (gefitinib) and in 2006 (erlotinib). These EGFR molecular targeted 
drugs, gefitinib and erlotinib, were initially approved as third-line or second-line therapy for patients with advanced NSCLC because of their therapeutic benefits, as suggested by randomised clinical trials. ${ }^{12-14}$ The recent National Comprehensive Cancer Network (NCCN) guideline $^{15}$ recommends gefitinib and erlotinib as the first-line therapy for EGFR mutation-positive patients with advanced NSCLC based on accumulating evidence showing a significant association between mutated EGFR and the clinical benefits of gefitinib and erlotinib. ${ }^{16-18}$ In light of rapid disease progression, timely access to pharmaceutical innovations such as targeted therapies is vital to patients with NSCLC. The new targeted therapies, gefitinib and erlotinib, have been reimbursed by Taiwan's National Health Insurance since 2004 and 2007, respectively, for patients with NSCLC who meet the above requirements based on evidence and clinical need.

Little is known about the effects of the introduction of new targeted therapies in Taiwan. This study is one of the first to address the gap by examining the changes in lung cancer-related survival rates and mortality following the launch of gefitinib and erlotinib.

\section{METHOD}

\section{Data sources}

We obtained data from 1994 to 2013 related to the lung cancer burden in Taiwan from the Taiwan Cancer Registry Database, which were compiled by the Health Promotion Administration, Ministry of Health and Welfare, Taiwan. ${ }^{19}$ The data include yearly incidence and mortality for various cancer types by age, gender and administrative division. Survival rates within several years of diagnosis of various cancer types are also available from the database.

Through the routine cancer case notification reminders and collection procedures each year, the sources of possible cancer cases and the cancer registration declaration database are combined. Health Promotion Administration calculates the completeness of cancer registration declarations in each year, approximately $98.44 \%$ in $2016 .{ }^{20}$ In addition, in accordance with the practice of the International Agency for Research on Cancer, percentage of death certificate only cases (DCO\%) and percentage of morphologically verified cases (MV\%) are used as quality indicators of the reporting data. In 2016, as a result of the data collection and comparison, the DCO $\%$ was $0.91 \%$, indicating that the coverage of the registration system was complete and the data quality in the system was consistent. In the same year, the MV\% of all cancer cases was $92.23 \%$, that of men was $90.79 \%$ and that of women was $93.89 \%$, indicating that the diagnosis of cancer cases was accurate. ${ }^{20}$ Use of these data for research purposes is exempt from review by the Institutional Review Board of the National Cheng Kung University Hospital in Taiwan.

\section{Measurements}

To examine the trends in lung cancer incidence, we collected the yearly number of new patients, crude incidence (per 100000 people) and age-standardised incidence (per 100000 people) of lung cancer by gender from 1994 to 2013. The global population in year 2000 was used to calculate the age-standardised incidence. ${ }^{21} \mathrm{In}$ addition, the yearly total of new patients with lung cancer (small cell lung cancer (SCLC) and NSCLC) according to stages at diagnosis was collected, and we calculated the rates of early-stage lung cancer over time. Diagnostic stages from 0 to 2 were considered as early stage, and stages 3 and 4 were categorised as late stage.

To evaluate the impacts of the launch of targeted therapies, 1-year and 2-year lung cancer survival rates by gender from 1994 to 2013 were collected. Furthermore, we collected the yearly number of deaths, the crude mortality (per 100000 people) and the age-standardised mortality (per 100000 people) for lung cancer by gender from 1994 to 2013.

\section{Statistical analysis}

To assess the yearly changes in lung cancer burden using the age-standardised incidence and rate of early-stage lung cancer at diagnosis as defined above, we used a time series design with the autoregressive integrated moving average (ARIMA) model, which was developed by Box and Jenkins. ${ }^{22}$ The model is generally referred to as an ARIMA(p,d,q) model, where parameters $p, d$ and $q$ are non-negative integers that refer to the order of the autoregressive, integrated and moving average parts of the model, respectively. These models are fitted to time series data either to better understand the data or to determine points in the series. ${ }^{23}$ We used the estimated rates from the ARIMA model for time series graphs.

To determine the effects of the launch of new targeted therapies for lung cancer on clinical outcomes, we also estimated the changes in the lung cancer-related 1-year and 2-year survival rates and age-standardised mortality following the launches of gefitinib and erlotinib using interrupted time series and segmented regression models, a strong quasiexperimental method. ${ }^{24-26}$ The method can provide strong evidence of causal effects because it takes into consideration the question of whether an intervention causes abrupt and measurable interruptions in a pre-existing trend. ${ }^{24} 27$ We used segmented linear regression models to estimate the effects of the launch of new targeted therapies on changes in the level and trend of both survival rates and age-standardised mortality. ${ }^{28}$ The basic model included terms to estimate the baseline level for each outcome (intercept) $\left(\beta_{0}\right)$, baseline trend (slope) $\left(\beta_{1}\right)$, changes in the level immediately after the drug launch $\left(\beta_{2}\right)$ and changes in the trend after the drug launch $\left(\beta_{3}\right)$ (see the following equation). ${ }^{24} 29$

$$
\begin{aligned}
& Y_{t}=\beta_{0}+\beta_{1} * \text { time }_{t}+\beta_{2} * \text { intervention }_{t}+\beta_{3} * \text { time }- \text { after } \\
& - \text { intervention }_{t}+e_{t}
\end{aligned}
$$

The models also controlled for autocorrelation. ${ }^{30}$ To identify the most parsimonious models, we used backward elimination and excluded non-significant terms $(p>0.05)$. 
Table 1 1994-2013 trends and 2014-2020 forecast of incidence of lung cancer in Taiwan

\section{Standardised incidence (per 100 000)}

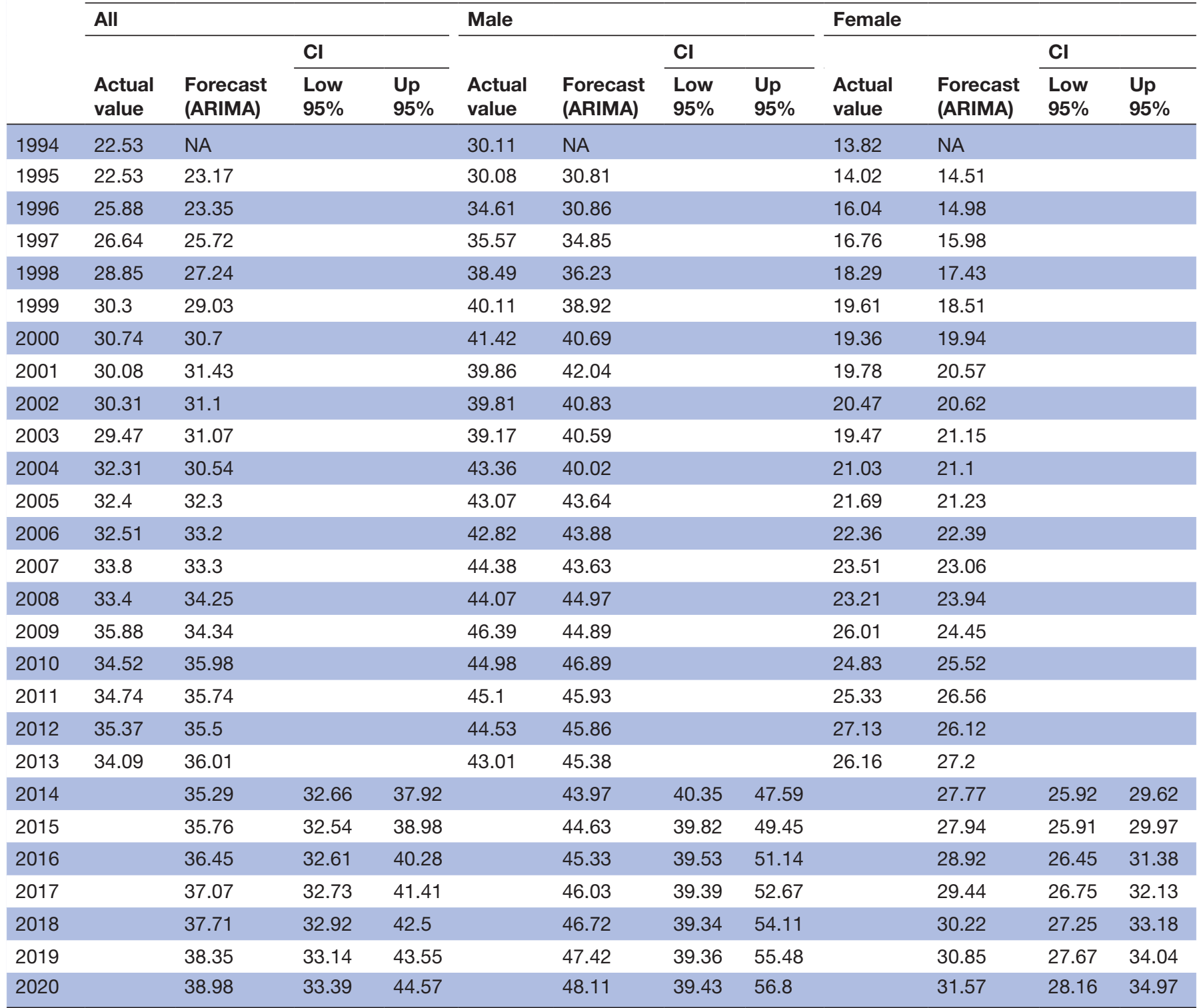

ARIMA, autoregressive integrated moving average; $\mathrm{Cl}$, confidence interval; NA, not available.

All analyses were carried out with SAS software V.9.4 (SAS Institute).

Patient and public involvement

Patients and the public were not involved in the design or planning of the study.

\section{RESULTS}

Table 1 presents the past trends (1994-2013) and future projections (2014-2020) of the age-standardised incidence of lung cancer by gender in Taiwan. The overall age-standardised incidence of lung cancer increased from 22.53 (per 100000 ) in 1994 to 34.09 in 2013, and it was projected to reach 38.98 by 2020 based on the trend during 1994-2013. By gender, the age-standardised incidence for males increased from 30.11 (per 100 000 ) in 1994 to 43.01 in 2013, and it was projected to reach 48.11 by 2020 ; the age-standardised incidence for females increased from 13.82 (per 100 000) in 1994 to 26.16 in 2013 , and it was projected to reach 31.57 by 2020.

Table 2 shows the past trends (1994-2013) and future projections (2014-2020) of the rate of early-stage lung cancer by type of lung cancer in Taiwan. The rate of early-satgeNSCLC at diagnosis grew rapidly from $12.63 \%$ in 2004 to $23.99 \%$ in 2013 , and it was projected to reach $32.95 \%$, based on the trend during 1994-2013. In contrast, the rate of early-stage SCLC at diagnosis declined from $4.78 \%$ in 2004 to $4.10 \%$ in 2013 and was projected to reach $3.11 \%$ by 2020 . 
Table 2 2004-2013 trends and 2014-2020 forecast of the rate of early-stage lung cancer at diagnosis in Taiwan

Rate of early-stage cancer at diagnosis (\%)

\begin{tabular}{|c|c|c|c|c|c|c|c|c|}
\hline & \multicolumn{4}{|l|}{ NSCLC } & \multicolumn{4}{|l|}{ SCLC } \\
\hline & \multirow[b]{2}{*}{ Actual value } & \multirow{2}{*}{$\begin{array}{l}\text { Forecast } \\
\text { (ARIMA) }\end{array}$} & \multicolumn{2}{|l|}{$\mathrm{Cl}$} & \multirow[b]{2}{*}{ Actual value } & \multirow{2}{*}{$\begin{array}{l}\text { Forecast } \\
\text { (ARIMA) }\end{array}$} & \multicolumn{2}{|l|}{$\mathrm{Cl}$} \\
\hline & & & Low $95 \%$ & Up 95\% & & & Low $95 \%$ & Up 95\% \\
\hline 1994 & NA & NA & & & NA & NA & & \\
\hline 1995 & NA & NA & & & NA & NA & & \\
\hline 1996 & NA & NA & & & NA & NA & & \\
\hline 1997 & NA & NA & & & NA & NA & & \\
\hline 1998 & NA & NA & & & NA & NA & & \\
\hline 1999 & NA & NA & & & NA & NA & & \\
\hline 2000 & NA & NA & & & NA & NA & & \\
\hline 2001 & NA & NA & & & NA & NA & & \\
\hline 2002 & NA & NA & & & NA & NA & & \\
\hline 2003 & NA & NA & & & NA & NA & & \\
\hline 2004 & 12.63 & NA & & & 4.78 & NA & & \\
\hline 2005 & 14.27 & 13.9 & & & 5.77 & 4.66 & & \\
\hline 2006 & 14.37 & 15.43 & & & 4.09 & 4.92 & & \\
\hline 2007 & 15.09 & 15.96 & & & 6.26 & 4.99 & & \\
\hline 2008 & 15.66 & 16.51 & & & 3.13 & 4.64 & & \\
\hline 2009 & 18.46 & 17.12 & & & 3.06 & 4.98 & & \\
\hline 2010 & 20.23 & 19.29 & & & 3.91 & 2.9 & & \\
\hline 2011 & 20.51 & 21.35 & & & 3.34 & 3.15 & & \\
\hline 2012 & 23.16 & 22.05 & & & 3.87 & 3.51 & & \\
\hline 2013 & 23.99 & 24.04 & & & 4.1 & 3.33 & & \\
\hline 2014 & & 25.38 & 23.36 & 27.39 & & 3.75 & 1.26 & 6.24 \\
\hline 2015 & & 26.61 & 24.13 & 29.09 & & 3.78 & 1.14 & 6.41 \\
\hline 2016 & & 27.89 & 24.93 & 30.84 & & 3.56 & 0.3 & 6.83 \\
\hline 2017 & & 29.15 & 25.81 & 32.49 & & 3.5 & 0.02 & 6.99 \\
\hline 2018 & & 30.42 & 26.72 & 34.11 & & 3.34 & NA & 7.22 \\
\hline 2019 & & 31.68 & 27.66 & 35.7 & & 3.25 & NA & 7.36 \\
\hline 2020 & & 32.95 & 28.63 & 37.26 & & 3.11 & NA & 7.52 \\
\hline
\end{tabular}

ARIMA, autoregressive integrated moving average; $\mathrm{Cl}$, confidence interval; NA, not available; NSCLC, non-small cell lung cancer; SCLC, small cell lung cancer.

\section{Survival rate following the launch of gefitinib}

Table 3 details the parameter estimates from the segmented regression models of changes in the lung cancer survival rate following the launch of targeted therapies. Overall, 1-year and 2-year survival rates increased by $10.18 \%$ (95\% CI $6.77 \%$ to $13.59 \%$ ) and $19.81 \%$ (95\% CI $14.90 \%$ to $24.71 \%$ ) 3 years following gefitinib's launch in 2003 (see figure 1). Among men, 1-year and 2-year survival rates increased by $10.70 \%$ (95\% CI $9.34 \%$ to $12.06 \%$ ) and $14.25 \%$ (95\% CI $3.27 \%$ to $25.24 \%)$; and among women, 1-year and 2-year survival rates increased by $14.82 \%$ (95\% CI $6.92 \%$ to $22.71 \%$ ) and $31.12 \%$ (95\% CI $15.64 \%$ to $46.60 \%$ ) (table 3) (figure 1).
Survival rate following the launch of gefitinib and erlotinib Overall, there were no significant changes in 1-year and 2-year survival rates 3 years following gefitinib and erlotinib's launch. Figure 1 shows the 1-year and 2-year survival rates of lung cancer in Taiwan over time. Among men, 1-year and 2-year survival rates did not change; however, 1-year and 2-year survival rates reduced by $13.34 \%(95 \%$ CI $-20.48 \%$ to $-6.20 \%)$ and $11.77 \%(95 \%$ CI $-22.36 \%$ to $-1.18 \%$ ) among women.

\section{Mortality following the launch of gefitinib}

Table 4 presents the parameter estimates from the segmented regression models of changes in the lung cancer mortality following the launch of targeted 


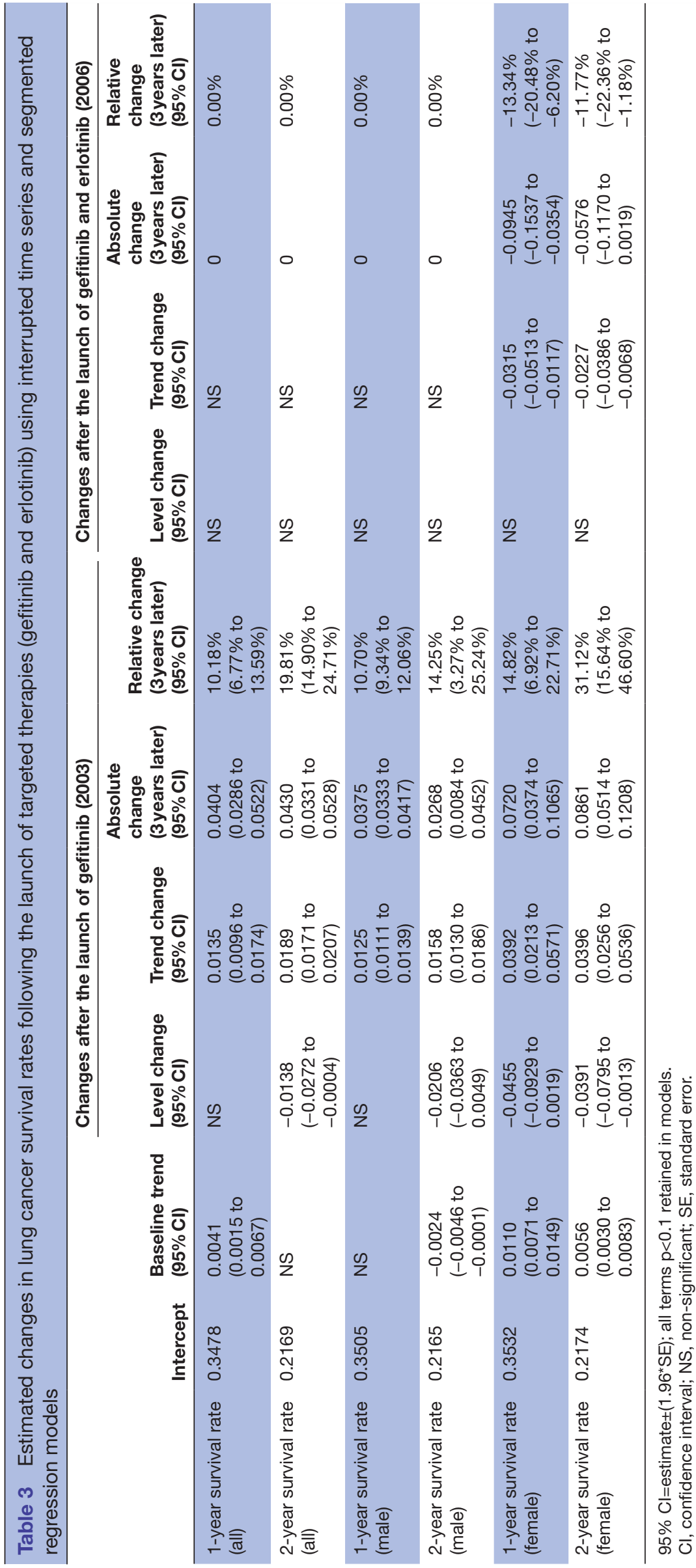

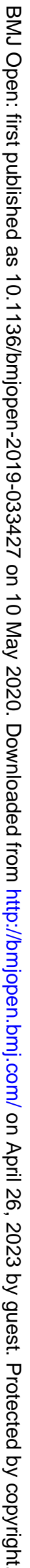




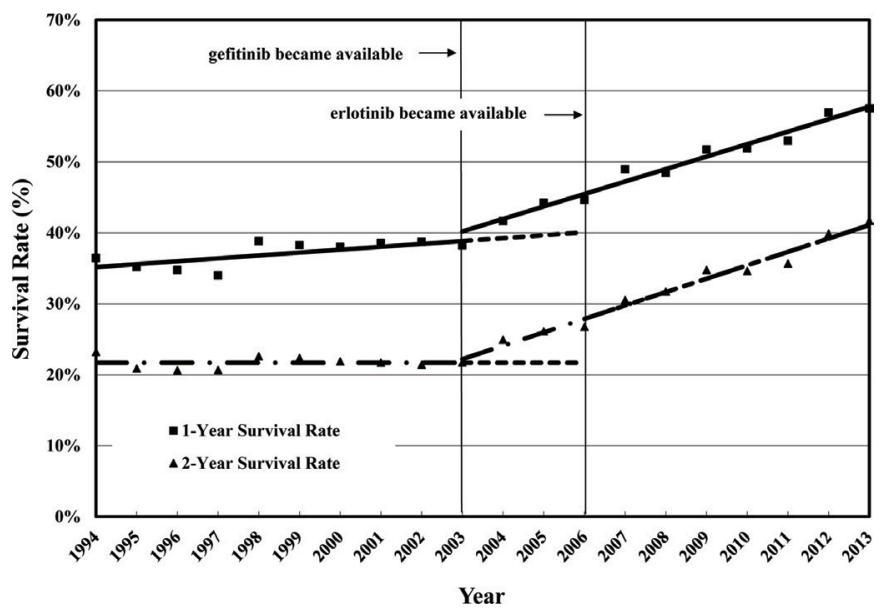

Figure 1 Yearly lung cancer survival rates in Taiwan (19942013).

therapies. Overall, mortality decreased by $5.97 \%$ (95\% CI $-8.20 \%$ to $-3.73 \%$ ) 3 years following gefitinib's launch in 2003 (see figure 2). Among men, mortality reduced by $5.40 \%$ (95\% CI $-10.08 \%$ to $-0.73 \%$ ), and among women, mortality decreased by $4.38 \%$ ( $95 \%$ CI $-7.50 \%$ to $-1.25 \%$ ) (table 4) (figure 2).

\section{Mortality following the launch of gefitinib and erlotinib}

Overall, there were no significant changes in lung cancer mortality 3 years following the launch of gefitinib and erlotinib in 2006. Figure 2 shows the overall lung cancer mortality in Taiwan over time. Among men, mortality reduced by $7.20 \%$ (95\% CI $-9.69 \%$ to $-4.71 \%)$ but mortality did not change significantly for women.

\section{DISCUSSION}

This study projected 7 years (2014-2020) of lung cancer incidence in Taiwan based on the observed incidence from 1994 to 2013 (20 years). We also projected rates of early-stage lung cancer at diagnosis for 2014 through 2020 based on the past trends. Furthermore, the present study is the first study to examine the national trend in lung cancer survival rates and mortality following the introduction of targeted therapies in Taiwan using an interrupted time series design.

We estimated an ongoing gradual increase in the agestandardised incidence of lung cancer for both men and women in Taiwan. According to our results, the overall incidence of lung cancer in Taiwan (35.4 per 100 000) was lower than that in the USA (38.4) and Canada (37.9) in 2012, but it was higher than that in the UK (30.0), Australia (27.0), Japan (24.6) and South Korea (28.7). ${ }^{31}$ Between 1994 and 2013, the age-standardised rate steadily increased by $42.84 \%$ for men and by $89.29 \%$ for women, and there was an estimated overall $51.31 \%$ growth rate (table 1). According to these trends, incidence would reach 48.11 per 100000 for men and 31.57 per 100000 for women by 2020. Our findings showing these increasing trends are similar to those of previous

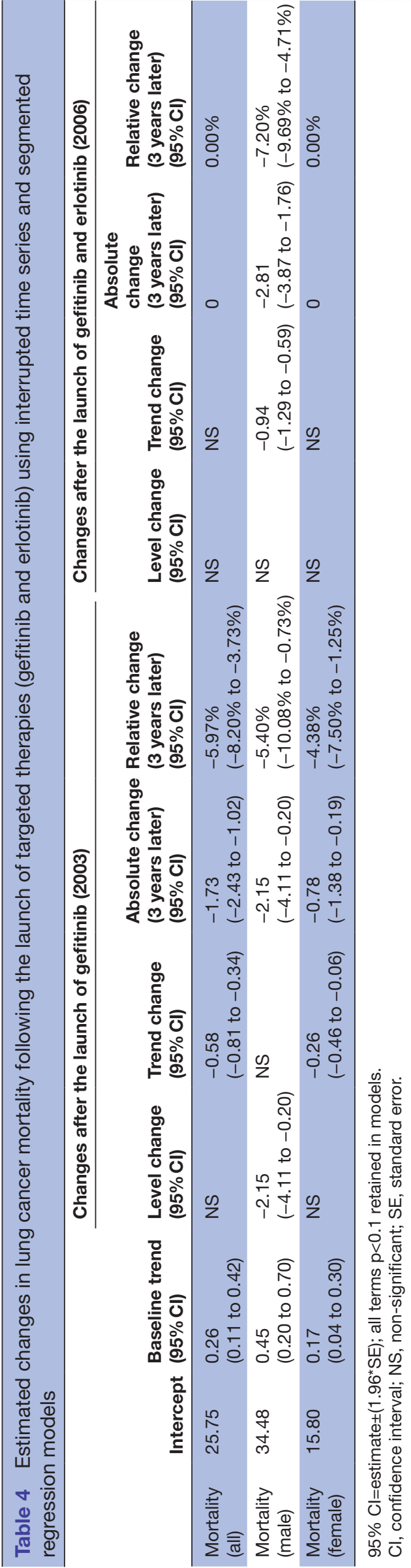




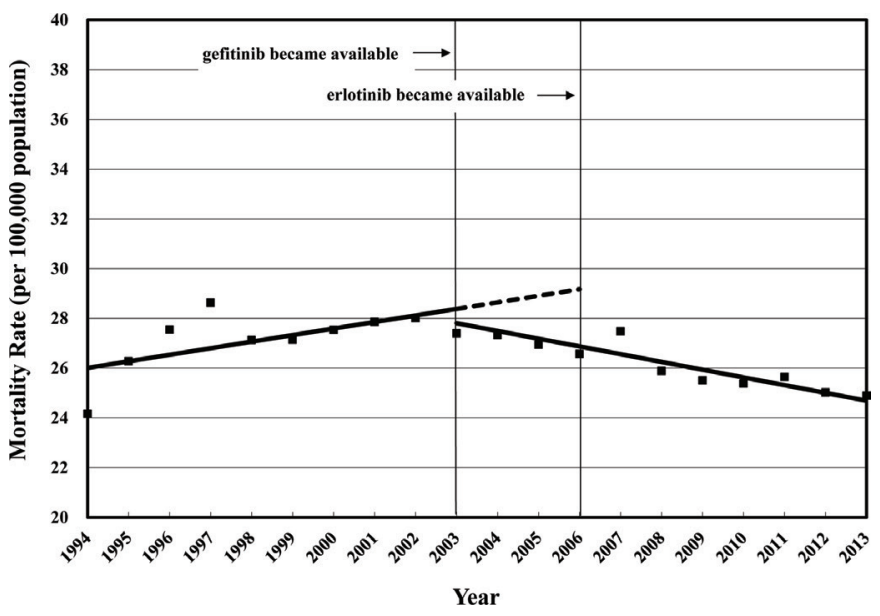

Figure 2 Yearly lung cancer mortality in Taiwan (1994-2013).

studies $^{32}{ }^{33}$ investigating earlier trends (up to 2008) in Taiwan. However, decreasing trends for both men and women in other countries have been observed. For example, lung cancer incidence decreased for both men and women in the USA (2004-2009), ${ }^{34}$ China (1997-2005 for men and 2001-2005 for women), ${ }^{35}$ Hong Kong (1983-2000) ${ }^{36}$ and Singapore (1980-2007). ${ }^{37}$ The incidence decreased for men but increased for women in the Czech Republic (1984-1998). ${ }^{38}$ Previous studies have provided evidence of a reduction in the prevalence of smoking following smoking bans. ${ }^{39-41}$ Lung cancer in non-smokers can be caused by exposure to radon gas, secondhand smoke, air pollution or other factors in addition to workplace exposure to asbestos, diesel exhaust or specific other chemicals that can also cause lung cancers in some people who do not smoke. ${ }^{42}{ }^{43}$ It is important to identify key drivers (other than smoking) of these increasing trends in Taiwan.

The incidence of lung cancer in Taiwan has increased over time and the rate of early-stage NSCLC at diagnosis gradually increased, but the ratio was still low (less than $25 \%$ ) until 2013, and the rate of early-stage SCLC at diagnosis has remained very low (less than $5 \%$ ) without a significant increase. There are almost no symptoms at the initial stage of lung cancer, thus, it is difficult to detect it early. ${ }^{44}$ However, the National Lung Screening Trial ${ }^{45}$ conducted by the National Institutes of Health in the USA found that the use of low-dose CT in highrisk groups for lung cancer could detect tumours earlier and reduce mortality by $20 \%$. Hence, the NCCN guideline recommends screening for people who smoke more than one pack of cigarettes a day, have smoked for more than 30 years, have quit smoking for less than 15 years or are 55-74 years old. ${ }^{46}$ The Taiwan Lung Cancer Society followed the NCCN guidelines and announced, in 2015, an expert consensus to further improve the early diagnosis rate. Early diagnosis through lung cancer screening might improve in the upcoming years.

For many years only chemotherapies were available for treatment of lung cancer. Then, the first targeted therapy, gefitinib, was approved for marketing in 2003, followed by the second targeted therapy, erlotinib, which became available in 2006. Compared with chemotherapies, most clinical trials have shown that when these two targeted drugs were used as the first line of treatment for advanced NSCLC with EGFR mutations, overall survival did not increase significantly, although progression-free survival increased significantly by $3-8$ months. ${ }^{167-50}$

We used real-world data to examine changes in lung cancer survival and mortality following the launch of these two targeted therapies in Taiwan. Gefitinib and erlotinib were reimbursed by Taiwan's National Health Insurance soon after marketing approval and their utilisation has increased rapidly over time. Our study of gefitinib and erlotinib prescribing trends during 2004-2013 ${ }^{51}$ found that the number of patients using gefitinib increased from $228(5.48 \%$ of all patients using antineoplastic agents) in 2004 to $5558(38.08 \%)$ in 2013; and the number of patients using erlotinib increased from $499(8.44 \%)$ in 2007 to $2984(20.44 \%)$ in 2013. Using rigorous research methods, the current study found that the 1-year survival rate increased by about $10 \%$, and the 2-year survival rate increased by about $20 \%$ in both men and women 3 years after the first targeted therapy (gefitinib) was launched. However, the subsequent survival rate did not change markedly after the launch of the second targeted therapy (erlotinib) because it is not a so-called 'breakthrough innovation', as was the case for the first targeted therapy. Together, findings from our prior and current studies suggest improved lung cancer survival and mortality following the launch of the first two targeted therapies and their increased use in Taiwan.

This study also estimated the age-standardised mortality of lung cancer for both men and women in Taiwan. We found that the overall mortality of lung cancer in Taiwan (25.0 per 100000 ) was lower than that in the USA (28.6), Canada (28.4) and the UK (25.4) in 2012, but it was higher than that in South Korea (21.3), Australia (18.5) and Japan (17.4) ${ }^{31}$ The mortality of lung cancer increased from 1994 to 2003 and decreased from 2003 to 2013 in Taiwan. However, it has gradually increased in Japan, has remained steady in Canada and Australia and has decreased in the USA and the UK. ${ }^{5152}$

The present study also found that mortality for both men and women was approximately $5 \%$ lower than expected 3years following the launch of gefitinib. However, mortality for men was $7 \%$ lower than expected 3 years following the launch of the second drug, erlotinib, without changes in mortality detected for women. Before the molecular testing of EGFR was established, the indication of gefitinib was considered mainly by using four factors: adenocarcinoma, non-smoker, Asian and female. It is possible that male patients gained more benefits after the molecular testing became routine practice in the clinic.

There are some limitations to this study. First, targeted therapies are only appropriate for patients with advanced NSCLC and EGFR mutation. Patients with advanced NSCLC account for about $64 \%$ of overall patients with 
lung cancer in Taiwan. ${ }^{5-8}$ Among them, approximately $40 \%-50 \%$ of patients have EGFR mutation. This study found improved lung cancer survival and mortality following the launch of targeted therapies, gefitinib and erlotinib. However, improvements in survival and mortality related to lung cancer may be due to other factors. Other diagnosis and treatment factors, including the availability and use of diagnostic tools (such as molecular testing), earlier diagnosis, sequential or combination treatment strategies, personalised care, multimodality care, palliative care support and psychological support, have roles in outcome improvements. Other factors, including patient's living habits and the global management of patients with cancer, may also contribute to the improvement in outcomes. Further studies considering these factors are needed. Second, pemetrexed, a cytotoxic chemotherapy, has been approved in Taiwan since 2004. Pemetrexed is indicated for non-squamous NSCLC, broader than EGFR-mutated NSCLC, thus, it could affect the mortality of lung cancer specially after the approval of the platinum-pemetrexed combination therapy in 2008. We did not have data on pemetrexed in this study to examine the survival or mortality of lung cancer in Taiwan following the launch of pemetrexed. However, based on our previous study ${ }^{53}$ of prescribing trends of antineoplastic agents in Taiwan, the prescription rate of folic acid analogues (including pemetrexed) during 2009-2012 remained steady (prescription rate from $16.7 \%$ to $17.13 \%$; growth rate of market share: $0.43 \%)$. Finally, we did not examine survival and mortality by lung cancer subtypes following the launch of targeted therapies. We did not have patient-level data to separate patients by lung cancer subtypes (NSCLC or SCLC) and disease severity (cancer stages). This study used data from the Taiwan Cancer Registry Database to estimate the two diagnostic indicators of lung cancer (incidences and rate of early-stage cancer at diagnosis) over time, and to evaluate changes in the two clinical indicators (survival rates and mortality) after the launch of targeted therapies. Notwithstanding these limitations, this study should provide an important basis for additional research.

\section{CONCLUSION}

In summary, our findings suggest that the incidence of overall lung cancer and rate of early-stage NSCLC at diagnosis increased in the past and that this trend is likely to continue in the future. Importantly, this study found that the survival rate and mortality of patients with lung cancer improved in Taiwan following the launch of targeted therapies (especially the initial one, gefitinib). However, further research is warranted to determine if these results are applicable to specific subtypes and stages of lung cancer.

\section{Author affiliations}

${ }^{1}$ International PhD Program in Biotech and Healthcare Management, College of Management, Taipei Medical University, Taipei, Taiwan
${ }^{2}$ Department of Pharmacy, National Taiwan University Hospital, Taipei, Taiwan ${ }^{3}$ Department of Internal Medicine, National Cheng Kung University Hospital, College of Medicine, National Cheng Kung University, Tainan, Taiwan

${ }^{4}$ Department of Internal Medicine, Tainan Municipal Hospital, Tainan, Taiwan ${ }^{5}$ Department of Population Medicine, Harvard Medical School and Harvard Pilgrim Health Care Institute, Boston, Massachusetts, USA

Contributors JCH, CFW and SCY conceptualised and designed the study. PCL and YCL provided suggestions for the research design from a clinical perspective. CFW collected data, performed the analyses and drafted the manuscript. JCH and CYL reviewed all data and revised the manuscript critically for intellectual content. All authors approved the final version for submission.

Funding This work was supported by Taiwan Ministry of Science and Technology grants (grant numbers: MOST 104-2320-B-006-005, MOST 106-2320-B-006-039).

Disclaimer The funders had no role in the study design, data collection and analysis, decision to publish or preparation of the manuscript.

Competing interests None declared.

Patient consent for publication Not required.

Ethics approval Use of data from the online Taiwan Cancer Registry Database for research purposes is exempt from review by the Institutional Review Board in Taiwan because the data used are public and aggregated population-level information.

Provenance and peer review Not commissioned; externally peer reviewed.

Data availability statement All data relevant to the study are included in the article. The authors obtained nationwide data from 1994 to 2013 (20 years) related to the lung cancer incidence in Taiwan from the Taiwan Cancer Registry Database, compiled by the Health Promotion Administration, Ministry of Health and Welfare, Taiwan.

Open access This is an open access article distributed in accordance with the Creative Commons Attribution Non Commercial (CC BY-NC 4.0) license, which permits others to distribute, remix, adapt, build upon this work non-commercially, and license their derivative works on different terms, provided the original work is properly cited, appropriate credit is given, any changes made indicated, and the use is non-commercial. See: http://creativecommons.org/licenses/by-nc/4.0/.

ORCID iD

Jason C Hsu http://orcid.org/0000-0002-8710-2338

\section{REFERENCES}

1 Ferlay J, Shin H-R, Bray F, et al. Estimates of worldwide burden of cancer in 2008: GLOBOCAN 2008. Int J Cancer 2010;127:2893-917.

2 World Health organization, International agency for research on cancer. Available: http://globocan.iarc.fr/Pages/fact_sheets_ population.aspx [Accessed Feb 2020].

3 World Health organization, International agency for research on cancer. Available: http://globocan.iarc.fr/Pages/fact_sheets_cancer. aspx [Accessed Feb 2020].

4 Taiwan's Cancer Registry Annual Report (2014) Bureau of Health Promotion Department of Health, ExecutiveYuan, Taiwan 2016. Available: http://www.hpa.gov.tw/Pages/Detail.aspx?nodeid=269\& pid $=7330$ [Accessed Feb 2020].

5 Pfizer. Oncology, lung cancer fact sheet 2012.

6 Reade CA, Ganti AK. Egfr targeted therapy in non-small cell lung cancer: potential role of cetuximab. Biologics 2009;3:215-24.

7 Alvarez M, Roman E, Santos ES, et al. New targets for non-small-cell lung cancer therapy. Expert Rev Anticancer Ther 2007;7:1423-37.

8 Ohe Y, Ohashi Y, Kubota K, et al. Randomized phase III study of cisplatin plus irinotecan versus carboplatin plus paclitaxel, cisplatin plus gemcitabine, and cisplatin plus vinorelbine for advanced nonsmall-cell lung cancer: Four-Arm cooperative study in Japan. Ann Oncol 2007;18:317-23.

$9 \mathrm{Kim} \mathrm{ST}$, Uhm JE, Lee J, et al. Randomized phase II study of gefitinib versus erlotinib in patients with advanced non-small cell lung cancer who failed previous chemotherapy. Lung Cancer 2012;75:82-8.

10 Sasaki H, Endo K, Okuda K, et al. Epidermal growth factor receptor gene amplification and gefitinib sensitivity in patients with recurrent lung cancer. J Cancer Res Clin Oncol 2008;134:569-77.

11 Schiller JH, Harrington D, Belani CP, et al. Comparison of four chemotherapy regimens for advanced non-small-cell lung cancer. $N$ Engl J Med 2002;346:92-8. 
12 Chen H-L, Shen L-J, Wei C-P, et al. Decision to adopt medical technology under the National health insurance system in Taiwan: case study of new molecular targeted drugs among non-small cell lung cancer patients. J Eval Clin Pract 2015;21:808-16.

13 Shepherd FA, Rodrigues Pereira J, Ciuleanu T, et al. Erlotinib in previously treated non-small-cell lung cancer. N Engl J Med 2005;353:123-32.

14 Cataldo VD, Gibbons DL, Pérez-Soler R, et al. Treatment of nonsmall-cell lung cancer with erlotinib or gefitinib. N Engl J Med 2011;364:947-55.

15 NCCN Clinical Practice Guidelines in Oncology. Non-Small cell lung cancer, P. 2. National comprehensive cancer network., 2013. Available: http://www.nccn.org/index.asp [Accessed in February, 2020]

16 Maemondo M, Inoue A, Kobayashi K, et al. Gefitinib or chemotherapy for non-small-cell lung cancer with mutated EGFR. $N$ Engl J Med 2010;362:2380-8.

17 Jiang $\mathrm{H}$. Overview of gefitinib in non-small cell lung cancer: an Asian perspective. Jpn J Clin Oncol 2009;39:137-50.

18 Mok TS, Wu Y-L, Thongprasert S, et al. Gefitinib or carboplatinpaclitaxel in pulmonary adenocarcinoma. $N$ Engl J Med 2009;361:947-57.

19 Cancer registration online interactive inquiry system, health promotion administration, Ministry of health and welfare, executive Yuan, Taiwan. Available: https://cris.hpa.gov.tw/pagepub/Home.aspx [Accessed Feb 2020].

20 National Health Promotion Administration,. Cancer registry annual report 2016, 2018. Available: ///C:/Users/User/Downloads/105\%E5\% B9\%B4\%E5\%A0\%B1.pdf [Accessed Feb 2020].

21 Møller B, Fekjaer H, Hakulinen T, et al. Prediction of cancer incidence in the Nordic countries: empirical comparison of different approaches. Stat Med 2003;22:2751-66.

22 Mills TC. Time series techniques for economists. Cambridge University Press, 1990.

23 Asteriou DH, Stephen G. ARIMA models and the Box-Jenkins methodology, applied Econometrics. Second ed. Palgrave MacMillan, 2011: 265-86.

24 Wagner AK, Soumerai SB, Zhang F, et al. Segmented regression analysis of interrupted time series studies in medication use research. J Clin Pharm Ther 2002;27:299-309.

25 Hsu JC, Lu CY, Wagner AK, et al. Impacts of drug reimbursement reductions on utilization and expenditures of oral antidiabetic medications in Taiwan: an interrupted time series study. Health Policy 2014;116:196-205.

26 CY L, Ross-Degnan D, Stephens P, et al. Changes in use of antidiabetic medications following price regulations in China (1999-2009). Journal of Pharmaceutical Health Services Research 2013:4:3-11.

27 Lu CY, Soumerai SB, Ross-Degnan D, et al. Unintended impacts of a Medicaid prior authorization policy on access to medications for bipolar illness. Med Care 2010;48:4-9.

28 Gillings D, Makuc D, Siegel E. Analysis of interrupted time series mortality trends: an example to evaluate regionalized perinatal care. Am J Public Health 1981;71:38-46.

29 Serumaga B, Ross-Degnan D, Avery AJ, et al. Effect of pay for performance on the management and outcomes of hypertension in the United Kingdom: interrupted time series study. BMJ 2011;342:d108.

30 Shadish WCT, Campbell D. Experimental and quasi-experimental designs for generalized causal inference Houghton Mifflin 2002.

31 European Medicines Agency. Erbitux: EPAR - Product Information, 2009. Available: http://www.ema.europa.eu/docs/en_GB/document library/EPAR___Product_Information/human/000558/WC500029119. pdf [Accessed 15 Jun 2017].

32 Chang JS, Chen L-T, Shan Y-S, et al. Comprehensive analysis of the incidence and survival patterns of lung cancer by histologies, including rare subtypes, in the era of molecular medicine and targeted therapy: a nation-wide cancer registry-based study from Taiwan. Medicine 2015;94:e969.

33 Chien C-R, Chen TH-H. A Bayesian model for age, period, and cohort effects on mortality trends for lung cancer, in association with gender-specific incidence and case-fatality rates. $J$ Thorac Oncol 2009;4:167-71.

34 Houston KA, Henley SJ, Li J, et al. Patterns in lung cancer incidence rates and trends by histologic type in the United States, 2004-2009. Lung Cancer 2014;86:22-8.

35 Chen W, Zhang S, Zou X. Evaluation on the incidence, mortality and tendency of lung cancer in China. Thorac Cancer 2010;1:35-40.

36 Au JSK, Mang OWK, Foo W, et al. Time trends of lung cancer incidence by histologic types and smoking prevalence in Hong Kong 1983-2000. Lung Cancer 2004;45:143-52.

37 Lim W-Y, Tan CS, Loy EY, et al. Lung cancer incidence in Singapore: ethnic and gender differences. Lung Cancer 2014;84:23-30.

38 Janout V, Siroky P, Novak J, et al. Lung cancer incidence in the Czech Republic: a time-trend study. Onkologie 2004;27:376-9.

39 Chiang $\mathrm{C}-\mathrm{Y}$, Chang $\mathrm{H}-\mathrm{Y}$. A population study on the time trend of cigarette smoking, cessation, and exposure to secondhand smoking from 2001 to 2013 in Taiwan. Popul Health Metr 2016;14:38.

40 Yang Y-N, Huang Y-T, Yang C-Y. Effects of a national smoking ban on hospital admissions for cardiovascular diseases: a time-series analysis in Taiwan. J Toxicol Environ Health A 2017;80:562-8.

41 Guo JL, Liao JY, Chang LC, et al. The effectiveness of an integrated multicomponent program for adolescent smoking cessation in Taiwan. Addict Behav 2014;39:1491-9.

42 Baser S, Shannon VR, Eapen GA, et al. Pulmonary dysfunction as a major cause of inoperability among patients with non-small-cell lung cancer. Clin Lung Cancer 2006;7:344-9.

43 Eguchi T, Bains S, Lee M-C, et al. Impact of increasing age on cause-specific mortality and morbidity in patients with stage I non-small-cell lung cancer: a competing risks analysis. J Clin Oncol 2017;35:281-90.

44 American Cancer Society. Cancer Facts \& Figures 2016. Atlanta: American Cancer Society, 2016.

45 Aberle DR, Berg CD, National Lung Screening Trial Research Team, et al. The National lung screening trial: overview and study design. Radiology 2011;258:243-53.

46 Ettinger DS, Wood DE, Akerley W, et al. NCCN guidelines insights: non-small cell lung cancer, version 4.2016. J Natl Compr Canc Netw 2016;14:255-64.

47 Inoue A, Kobayashi K, Maemondo M, et al. Updated overall survival results from a randomized phase III trial comparing gefitinib with carboplatin-paclitaxel for chemo-naïve non-small cell lung cancer with sensitive EGFR gene mutations (NEJ002). Ann Oncol 2013;24:54-9.

48 Mitsudomi T, Morita S, Yatabe Y, et al. Gefitinib versus cisplatin plus docetaxel in patients with non-small-cell lung cancer harbouring mutations of the epidermal growth factor receptor (WJTOG3405): an open label, randomised phase 3 trial. Lancet Oncol 2010;11:121-8.

49 Zhou C, Wu Y-L, Chen G, et al. Erlotinib versus chemotherapy as first-line treatment for patients with advanced EGFR mutationpositive non-small-cell lung cancer (optimal, CTONG-0802): a multicentre, open-label, randomised, phase 3 study. Lancet Oncol 2011;12:735-42.

50 Rosell R, Carcereny E, Gervais R, et al. Erlotinib versus standard chemotherapy as first-line treatment for European patients with advanced EGFR mutation-positive non-small-cell lung cancer (EURTAC): a multicentre, open-label, randomised phase 3 trial. Lancet Oncol 2012;13:239-46.

51 Hsu JC, Wei C-F, Yang S-C. Effects of removing reimbursement restrictions on targeted therapy accessibility for non-small cell lung cancer treatment in Taiwan: an interrupted time series study. BMJ Open 2019;9:e022293.

52 Global Health Data Exchange database, The Institute for Health Metrics and Evaluation (IHME). An independent global health research center at the University of Washington. Available: http:// ghdx.healthdata.org/ [Accessed Feb 2020].

$53 \mathrm{Hsu}$ JC, Lu CY. Longitudinal trends in use and costs of targeted therapies for common cancers in Taiwan: a retrospective observational study. BMJ Open 2016;6:e011322. 